\title{
Alimentary Bolus
}

National Cancer Institute

\section{Source}

National Cancer Institute. Alimentary Bolus. NCI Thesaurus. Code C125189.

A soft mass or lump of chewed food that is passed from the mouth into the esophagus and the stomach. 